\title{
Memoria y final del juego en Una noche cualquiera de Susana Torres Molina
}

\section{Reina Ruiz}

La obra de la dramaturga argentina Susana Torres Molina, Extraño juguete, publicada en 1978 y ampliamente representada desde la fecha de su producción, presenta interesantes puntos de conexión con una de las más recientes obras de la autora, Una noche cualquiera, ganadora del XVIII Premio de Teatro "Hermanos Machado" de Sevilla (1998). A pesar de la distancia temporal y las diferencias temáticas y estructurales que median entre ambas obras, éstas comparten el elemento metadramático como uno de los aspectos más importantes para su análisis. Como contrapunto a Extraño juguete, en este ensayo se valorará el metadrama en Una noche cualquiera en su función de juego y recurso dramático, y como instrumento ideológico ligado a la recuperación de la memoria histórica argentina.

Richard Hornby ha estudiado ampliamente el concepto de metadrama y ha añadido nuevas perspectivas a los estudios de Lionel Abel, Sydney Homan y Robert Nelson, entre otros. ${ }^{1}$ Hornby indica que el metadrama es un elemento artístico que da un paso más allá del consabido teatro dentro del teatro, y lo considera un procedimiento a través del cual se descubre una verdad (32). Uno de los puntos de mayor interés en las dos obras de Torres Molina es la utilización del metadrama como estrategia que desvela verdades diferentes de un mismo mundo separado por veinte años de distancia: la Argentina de los 70, al comienzo de la dictadura militar, y la Argentina en democracia de los años noventa. ${ }^{2}$

Tanto en Extraño juguete como en Una noche cualquiera el marco metadramático no se desvela desde un principio. En Extraño juguete, el metadrama es el juguete ${ }^{3}$ con el que se entretienen dos damas de alta sociedad que juegan a representar los distintos papeles y situaciones que un guionista contratado, el señor Miralles, elabora para su divertimento. El metadrama, es decir, el texto dramático de Miralles, funciona como juguete y protagonista de 
Extraño juguete. La ilusión teatral se quiebra cuando Miralles/autor y actor dramático en su papel de Maggi/vendedor ambulante, se salta el guión y sale de escena precipitadamente para ir al baño. De repente, como señala Ricardo Monti en el prólogo de la edición de 1978, hay un inesperado cortocircuito que da paso a la verdad (7). Perla y Angélica, las dos hermanas solteronas víctimas de un desaprensivo que se introduce en la casa como vendedor ambulante, son en realidad dos burguesas aburridas que contratan los servicios de Miralles, creador del juguete y a la vez actor que participa en el juego diseñado por él mismo. El cortocircuito tiene lugar en el momento de clímax cuando el vendedor ambulante, a modo de domador de circo, toma las riendas de la situación y obliga a las dos hermanas a subirse a una silla: "Claro, las nenas se portan mal para que papito les haga chas-chas en la cola, eh. A ver cómo se bajan las bombachitas. ¡Vamos! ¡Vamos! Rapidito, que las nenas tienen que irse a dormir. Vamos, rapidito, rapidito" (70). Los indicios de violencia sexual acentúan la situación de incomodidad"Angélica y Perla con las polleras levantadas y las bombachas bajas se quedan esperando el golpe" (70), momento que Maggi aprovecha para abandonar el escenario y provocar el corte en el punto culminante, cuando la escena de abuso sexual a manos de un degenerado es inminente. El grito desconcertante de Perla: “iSeñor Miralles!” (71) rompe la tensión dramática y hace partícipe al público de que todo ha sido una representación fingida, concluyendo el juego de forma abrupta.

La crítica ha coincidido en señalar la importancia del elemento metadramático en Extraño juguete. David William Foster subraya el aspecto socio-económico de la obra que remite a las formas capitalistas de producción del arte y de la cultura ("Identidades" 78). Miralles escribe sus guiones al servicio de dos señoras de la alta sociedad que imponen sus gustos y exigencias al escritor/ actor asalariado. Jacqueline Eyring Bixler afirma que las estrategias metateatrales de Extraño juguete trascienden los límites de la realidad y la ilusión y marcan las relaciones entre las clases, el consumismo, el arte y los sexos ("For Women" 217). Bixler ha observado también que, mediante el juego como recurso estructural o como tema central, Torres Molina ataca sutilmente a las estructuras de poder que dictan las reglas del juego para poder sobrevivir en sociedad ("Games and Reality” 22). Catherine Larson añade que la autora juega con las palabras, las cuestiones de género, la problemática sociocultural y el teatro mismo, obligando al público a participar activamente en la reinterpretación de la realidad y obligar a reconsiderar los instrumentos de comunicación que usamos para comunicarlo (109). En cualquier caso, el recurso del teatro dentro del teatro refleja y expresa 
el cinismo de la sociedad ante la vida, que en última instancia indica que el mundo real en el que vivimos no deja de ser sino mera ilusión, simple teatro (Hornby 45).

En Extraño juguete el marco metateatral se revela casi al final de la obra dejando al descubierto el juguete y la clara estructura de teatro dentro del teatro. El escenario desmantelado de la vivienda de Perla y Angélica muestra la realidad del almacén vacío donde Mónica y Silvia se divierten con sus juegos teatrales particulares y revelan su verdadera identidad, mientras Miralles negocia tímidamente sus emolumentos e intenta vender su nuevo material. Desde el principio de Una noche cualquiera el diseño no convencional del escenario marca el distanciamiento 4 que "transformará al espectador emotivo en observador intelectual" (Luzuriaga 48). El escenario está formado por un espacio central en el que desembocan cuatro pasillos orientados en la dirección de los puntos cardinales. Antes del comienzo del espectáculo formal los personajes entran y salen del espacio central utilizando los pasillos, mientras el público se sienta en la zona del pasillo sur por el que accede al teatro. La presencia de cuatro cámaras de video (dos enfocadas al escenario; dos enfocadas al público) y seis pantallas (cuatro reproducen las imágenes sin audio que toman las cámaras; dos están conectadas a canales de aire) contribuye a hacer al público parte activa del espectáculo, a la vez que rompe la ilusión teatral desde el principio. Uno de los efectos que el elemento metateatral ejerce en el espectador es la capacidad de ver doble, lo cual conlleva diferentes niveles de percepción (Hornby 32). En Una noche cualquiera las imágenes que reproducen los monitores multiplican las perspectivas del público que no sólo percibe lo que ocurre en escena, sino además puede verse a sí mismo, es decir, sus reacciones, su incomodidad, su horror; imágenes que, de alguna manera, forman parte de otro espectáculo virtual.

En Una noche cualquiera el metadrama se plantea de forma compleja en el entramado de imposturas que dos desconocidos llevan a cabo al introducirse de forma subrepticia en una casa de gente adinerada, y los diferentes papeles que representan. Dentro de la categoría metateatral del "role playing within the role" (el papel dentro del papel o juego de papeles), Richard Hornby distingue tres tipos: voluntario, involuntario y alegórico (73). ${ }^{5}$ En esta obra el juego de papeles se presenta como un acto voluntario, ya que los dos intrusos son conscientes de que están adoptando personalidades fingidas e improvisando diferentes papeles, aunque ni el público ni el resto de los personajes en escena saben quiénes son los dos individuos hasta el final cuando éstos revelan sus motivaciones. 
El comienzo del drama presenta una situación banal de dos parejas que se reúnen para pasar la velada, y que rápidamente degenera en un conflicto de celos y crisis de relación de pareja. Luli, con la connivencia de su amiga Marisa, lo ha calculado todo para quedarse a solas con Marcelo (actor de moda y amigo de su compañero), de quien se ha encaprichado. Pepe se da cuenta de las intenciones de Luli y sale de la casa furioso. A Marcelo comienza a gustarle el plan de Luli y le sigue el juego de seducción y deseo en una noche que como él mismo indica "no es una noche cualquiera" (26). Sin embargo, el inicio de un prometedor menage à trois se interrumpe bruscamente con el sonido del timbre de la puerta. ${ }^{6}$

A partir de aquí la acción toma un rumbo inesperado y comienzan las supercherías de los desconocidos, Sandro y Musetti, que consiguen colarse en la casa. Primero, sacan las credenciales de policía para intimidar y amedrentar a los presentes, justificando su brusca entrada con una supuesta "denuncia," una simple "cuestión de rutina" (29). Luego, la visita rutinaria comienza a tomar un tinte violento al cortar la comunicación con el exterior y ordenar la entrega de los teléfonos móviles amenazándoles con una navaja. En su papel policial, Musetti inicia un interrogatorio de rigor con Marisa, aunque éste se queda en un careo fingido en su forma y en su fondo, ya que las preguntas toman un cariz imprevisto cargado de insinuaciones sexuales. ${ }^{7}$ La escena de confesión íntima se lleva a cabo en el pasillo norte ${ }^{8}$ separada de la acción simultánea del espacio central donde el resto de los personajes siguen las órdenes de Sandro. Éste les obliga a cantar a voz en grito un tema de Fito Páez ${ }^{9}$ al ritmo desenfrenado de una batería imaginaria, golpeando en la mesa con diversos objetos. Como indican las acotaciones, "el clima central es cada vez más frenético" (44), y de nuevo, el sonido inesperado del timbre de la puerta rompe la tensión dramática y paraliza la escena.

El retorno de Pepe revela que los falsos policías son en realidad dos conocidos que él contrató para asustar a sus amigos y vengarse de Luli. Sin embargo, terminado el trabajo los dos intrusos se resisten a bajarse de su papel y continúan dominando el juego de subyugación y violencia para obligarles a confesar los secretos de su pasado. Como Fernando Savater señala: "La verdadera tortura nace con el interés por la intimidad del otro, es decir, nace con la pregunta" (18). Sandro y Musetti torturan a sus víctimas con repetidas preguntas para sonsacar la verdad por medio del dolor; dolor en un significado "que abarca toda la gama de tormentos físicos, psíquicos o morales" (Savater 21). 
La violencia y la intimidación se llevan a cabo por diferentes métodos, y su intensidad va in crescendo a lo largo de la obra. Obligan a Pepe y Marcelo a quitarse la ropa; rocían el suelo con un bidón de queroseno; en varias ocasiones la violencia física se queda en un simple amago: Sandro levanta un puño amenazador que nunca descarga sobre su víctima. Más adelante se sustituye la navaja por el uso de pistolas para jugar a una variante del juego de la Gran Ruleta: Pepe tiene que disparar contra Marcelo, o Sandro le matará a él. Sin embargo, el revólver sin balas se presenta como otro amago de violencia física, como el puñetazo que Sandro nunca descarga, pero que surte el efecto deseado: provocar el pánico y crear un sentimiento de vulnerabilidad en sus víctimas. Todo ello, añadiendo el abuso verbal (gritos, órdenes, insultos, amenazas), desemboca en una escena de pánico y conmoción para las dos parejas. ${ }^{10}$

Las humillaciones continúan hasta que consiguen que cada uno de los personajes hablen, todos tienen un secreto que confesar sobre la época de finales de los setenta. ${ }^{11}$ La confesión de Marcelo marca una transformación en el comportamiento de Sandro y Musetti, como si de repente dejaran de actuar y recuperaran su identidad. En ambos individuos desaparece la actitud fría, manipuladora y cínica para presentar otra personalidad, la de dos supervivientes de la época de terror y tortura que vivió Argentina entre 1976 y 1983. Marcelo, confidente de la policía, denunció al hermano y la cuñada de Sandro y Musetti. Éste sería el momento del cortocircuito en que la revelación de estos hechos da paso a la verdad: "los cuatro están paralizados" (100) y comprenden el por qué de todo el montaje que los falsos policías han construido para una velada tan particular:

A MARTÍN y a su mujer embarazada, les entraron en la casa, les rompieron y robaron de todo, después se los llevaron, los torturaron y se ensañaron especialmente con ellos, porque LAURA era judía.Y a MARTÍN como era actor lo trataban de puto. Y después de tenerlos mucho peor que animales, peor que basura, después de humillarlos, de aterrorizarlos durante meses...los mataron.... Ustedes que hace sólo una hora que están con nosotros... juna hora!... y que ni siquiera los hemos tocado... y no precisamente por falta de ganas... ¿pueden ahora decirnos por qué? (Silencio). ¿Por qué? (Silencio). ¿Por qué (Gritando). iiiPor qué!!! (103)

Los victimarios, verdugos que representan el papel de degenerados y bestias torturadoras que se divierten con el sufrimiento ajeno, se tornan en víctimas de esa misma guerra, incapaces todavía de asimilar la brutalidad del régimen dictatorial y borrar la memoria del pasado. 
Vicente Palermo designa la memoria fijada como un tipo de memoria imborrable que condiciona el presente: "sus sujetos se relacionan entre sí y con el mundo a partir del sentimiento originado en los agravios sufridos y de la imposibilidad de olvidarlos o perdonarlos" (174). Sandro y Musetti sufren ese tipo de memoria traumática que les impide olvidar la muerte de sus familiares por la que siguen clamando justicia. Los dos hermanos no están en escena para señalar una problemática social (la inseguridad ciudadana o la corrupción del cuerpo policial), sino para declarar públicamente que cualquier día, todos los días son buenos para hacer memoria histórica, para no olvidar el pasado de una dictadura atroz, las torturas y los desaparecidos. Ambos personajes se niegan a olvidar y obligan a recordar, a mantener viva la memoria de las injusticias y la barbarie. Como Bruno Groppo y Patricia Flier indican, las dictaduras militares de los años 70 y 80 en el Cono Sur han dejado un rastro de problemas abiertos que siguen traumatizando a una parte de la sociedad: "los desaparecidos, las leyes de amnistía, la imposibilidad de establecer la verdad, la falta de sanción e impunidad han provocado como consecuencia que ese pasado, imposible de cerrar, continúe atormentando el presente" (13). Los diferentes discursos sobre la reconciliación han servido para legitimar el olvido y aceptar una amnesia colectiva en beneficio del bien común (37).

A lo largo de la obra se advierte el sentimiento de frustración de Sandro y Musetti y su búsqueda de justicia, aunque ésa sea su justicia particular e ilégitima, y de alguna manera, se evidencia el deseo de venganza por unas acciones del pasado que continúan impunes en el presente:

Y cuando la justicia no viene de donde tiene que venir entonces puede venir de cualquier otro lado, como un boomerang.... Ustedes, insectos con poder, han seguido lanzando mierda al techo, alegremente. Y esa mierda, lo quieran o no, les guste o no, les va a volver, les está volviendo, directo a ustedes. Esta vez en forma de dos tipos que tocan el timbre, una noche cualquiera...." (el énfasis es mío, 101)

Su sed de justicia rememora la aprobación de las leyes de Punto Final y Obediencia Debida decretadas por el presidente Raúl Alfonsín en 1987. Al final, la amnistía, aprobada bajo el gobierno de Carlos Menem en 1989, libraba de toda responsabilidad a los militares que participaron en la represión (Funes 58). Se pretendía el olvido, el perdón por las atrocidades pasadas para seguir adelante con el proceso democrático argentino. Para Sandro y Musetti, sin embargo, no ha habido olvido ni perdón. 
Las humillaciones ejercidas contra las dos parejas y las amenazas con prender fuego a la casa funcionan como una forma de redención y purificación del dolor que todavía sienten los falsos policías. Musetti, quien juega un papel ambivalente de torturador implacable y de ciudadano atormentado por los recuerdos del pasado, quiere escucharles pedir perdón mientras va rociando queroseno a su alrededor:

(Conmocionado). ¡No les creo, no les creo nada!... ¡Sólo quieren salvar el pellejo... ; y nosotros queremos que salven sus almas!... ¡Queremos que pidan perdón de acá! (Se golpea el pecho). ¡Bestias! Necesitamos ver aparecer una chispa de conciencia, dentro de esos cadáveres! [...] que se den cuenta de una vez, de todo el dolor que causaron (llorando con rabia)... ¡Y que dejen de actuar como si no hubiera pasado nada! (recomponiéndose). Una chispa de conciencia... una sola chispa y... (con un gesto de las manos imita una llamarada) ¡la redención! (104-05) ${ }^{12}$

La función termina con las cuatro víctimas arrodilladas, desnudas y atenazadas por el miedo a ser quemadas en una pira expiatoria, balbuceando una letanía de perdones y excusas a modo de última oración antes de la muerte:

Estoy arrepentido, de verdad, creánme!... ¡No me hagan daño, por favor!... ¡Ya entendi, ya entendí!... ¡Les juro que yo no hice nada!... ¡Tengan un poco de piedad!... ¡Tengo miedo!... ¿Qué nos van a hacer?... Dénme otra oportunidad, se lo suplico/... ¡Perdón, perdón!... ¡Yo también tengo hijos!... ¡Nunca más, les juro que nunca más!... (105)

Una vez conseguido su propósito, los dos desconocidos abandonan la estancia sin llevarse nada. Musetti deja la pistola en el suelo, y Sandro se da la vuelta para disparar con el gesto de la mano cuatro veces: un balazo imaginario por persona. Finalmente, logran purgar su rabia y sus frustraciones, satisfechos con la situación dantesca que han provocado: sus cuatro víctimas en un amasijo, retorciéndose de miedo ante el fuego inminente. La escena evoca los métodos del teatro de la crueldad que creara Antonin Artaud, y que asocia el teatro al peligro y la crueldad como procedimiento para echar los demonios del cuerpo. La representación dramática para Artaud debe ser un acto de iniciación que provoque miedo y sobrecogimiento en el espectador, lo cual le colocará en la posición de comprender nuevas verdades y órdenes (Fowlie 205-06). A su vez, este momento de clímax funciona como otra de las categorías metateatrales que Hornby denomina "la ceremonia dentro del teatro," y que 
incluye fiestas, bailes, juegos, rituales y procesiones (49). Evidentemente, la ceremonia no siempre tiene una connotación positiva de regocijo y celebración. Para comprender el uso de la ceremonia en el drama hay que remontarse a la ceremonia desde el origen de la humanidad, y como Susanne Langer indica, ya en los rituales primitivos interviene el sufrimiento y la violencia (Hornby 50). ${ }^{13}$ En Una noche cualquiera la ceremonia final del fuego expiatorio evoca un autoexorcismo simbólico en el que Sandro y Musetti espantan los espíritus malignos, la rabia y la sed de venganza que los mueve a llevar a cabo su representación truncada.

La interpretación de Sandro y Musetti y las diferentes identidades que adoptan no son un mero juguete para entretenimiento del público. Ellos mismos son conscientes de su papel metateatral, y al final, sus víctimas son en realidad los verdugos que controlan sus vidas:

Esto que ves aquí, es realidad virtual. Y nosotros estamos, porque ellos pusieron un diskette. Están aburridos y como saben que siempre se portan mal, quieren jugar a que alguien los castiga. Así que nosotros estamos acá sólo obedeciendo órdenes. La verdad es que ellos controlan la situación, pero lo más increible de todo es... que no lo saben. $(80-81)$

A diferencia de Extraño juguete, en el que todos los personajes son conscientes del juego metateatral (excluyendo al público hasta el momento del ya mencionado cortocircuito), en Una noche cualquiera sólo los dos intrusos participan de esa autoconsciencia; ni él público, ni el resto de los personajes son capaces de deslindar la realidad de la ilusión y desvelar la verdadera identidad de Sandro y Musetti. Como Mario Cabezas indica, la categoría metateatral del papel dentro del papel "es una forma de descubrirnos a nosotros mismos," de llegar a descrubrir un "yo" escondido que se refleja en las formas y modos de un papel diferente (80). El personaje que sufre dicha transformación (metagonista ${ }^{14}$ ) pasa por diferentes estados psicólogicos para alcanzar el cambio. En ese sentido, y, como Hornby sugiere, el juego de papeles es una estrategia que sirve para delinear un personaje y mostrar no sólo quién es sino también quién quiere ser (67). El metagonista se presenta como un ente de gran imaginación que se rebela a la realidad que le ha tocado vivir y utiliza métodos transgresores para "tratar de cruzar el límite impuesto" y lograr su fin. Así, estos personajes "transgreden ciertas leyes sociales, morales o políticas, se auto-dramatizan y dramatizan a los demás" (Cabezas 81). Sandro y Musetti son un par de inadaptados que se rebelan a la situación política y social del momento, y utilizan su imaginación 
para improvisar sus papeles y los métodos de tortura psicológica que imponen a sus víctimas.

El metadrama, el juego que representan los falsos policías funciona como instrumento capaz de activar la memoria, evitar la amnesia, y permitir reconstruir el pasado para perdonar en el presente. Ellos no buscan a los que perpetraron la muerte de sus familiares, sino a quienes facilitaron la situación de injusticia, violencia y barbarie del régimen dictatorial argentino. Denuncian el olvido de algunos sectores, individuos y grupos sociales que de un modo u otro, mediante el silencio o la acción, apoyaron la violencia represiva de la dictadura argentina entre 1976 y 1983. Las acusaciones de los dos hermanos y la situación de tortura y abuso psicológico que imponen a sus víctimas se multiplican mediante las pantallas que reproducen imágenes del escenario y del público. La presencia de las cámaras sugiere que las acusaciones de Sandro y Musetti van dirigidas a los personajes en escena, pero también al público y a todos aquellos que de alguna manera, aun con su silencio (como el silencio que reina en la sala durante la representación) acataron los abusos de poder y las acciones de violencia desmedida. Sandro y Musetti obligan a recordar a sus víctimas, y a la vez al público presente que puede llegar a experimentar el mismo sentimiento de angustia al recordar acontecimientos, para algunos, enterrados en el olvido producto de una amnesia buscada o de otros mecanismos de inhibición de la memoria.

Extraño juguete y Una noche cualquiera marcan dos épocas en la dramaturgia de Susana Torres Molina. La primera señala el éxito de la autora al principio de su carrera; la segunda, 20 años después, consolida su posición de honor en el panorama teatral argentino. El uso del metadrama en ambas revela verdades distintas. David William Foster ha señalado que Perla y Angélica utilizan el juguete con la seguridad de que no se convertirá en realidad. Su placer estriba en saber que todas las emociones fuertes desaparecerán cuando termine la representación, y que de nuevo serán ellas quienes tomen las riendas en su realidad cotidiana. El teatro no deja de ser sino mero teatro, es decir, un juego que puede resultar provocativo pero que nunca se torna en arma amenazadora ("Two Feminist" 155-56). La estructura circular de Extraño juguete anticipa la proliferación de otros metadramas, nuevos juegos y juguetes con los que seguir divirtiendo a dos señoras aburridas; juguetes que no cambiarán su posición social e identidad. Miralles continuará tejiendo sus ficciones a las órdenes de quienes ostentan el poder ecónomico y social. Sin embargo, en Una noche cualquiera el juego de imposturas sí se convierte en un arma arrojadiza que acusa, culpa y busca la justicia que se les ha negado a Sandro y Musetti por vía de la legalidad. 
El metadrama consigue llegar a una verdad, la de recuperar la memoria y obligar a recordar a sus víctimas los abusos de poder que se perpretaron durante la dictadura. Los dos intrusos desean que el juguete sí se convierta en realidad, que sus tiros imaginarios se materialicen en una justicia que la legalidad les ha negado. Si como indica Fernando Savater, torturar tiene la finalidad pedagógica de "enseñar, explicar, grabar a sangre" (21), ambos personajes han conseguido sus objetivos, aunque de forma momentánea. La lección ha terminado, su actuación se da por finalizada, ha servido para aplacar su furia interior y satisfacer su sed de justicia, aunque como la historia lo demuestra, de forma transitoria. ${ }^{15}$

Una noche cualquiera plantea a su vez serias cuestiones éticas y morales que el drama no resuelve. Todos los personajes representan papeles de una moralidad ambigua. Las dos parejas torturadas y humilladas que se presentan al principio como personajes livianos motivados por el sexo, el dinero, las drogas o el alcohol son víctimas de dos desaprensivos que hurgan en sus conciencias de forma violenta. Y a la vez, los dos intrusos, aparentes mafiosos y delincuentes, son víctimas de la dictadura, supervivientes del terrorismo de estado, cansados de esperar una justicia que no viene de donde tiene que venir. La obra señala los dos sectores de oposición en la sociedad argentina: el de aquellos que se resisten a olvidar y continúan buscando la justicia donde sea para poder seguir viviendo, y el de quienes han dado la espalda al pasado. El final de este juego insinúa el inicio de otros juegos en los que se seguirán interpretando papeles de resistencia al olvido, y se abogará por la recuperación de la memoria como único camino para llegar a la reconciliación por medio de la justicia. Los métodos de recuperación de la memoria y las formas de hacer justicia son asuntos que quedan en el aire en Una noche cualquiera, y se representan de forma paralela a las imágenes borrosas que proyectan los monitores conectados a canales de aire; lo que consigue el metadrama es presentarse como un instrumento ideólogico capaz de despertar la conciencia de los dormidos, de quienes siguen viviendo como si no hubiera pasado nada, aunque los métodos utilizados sean cuestionables. El proceso no ha terminado.

\section{University of Arkansas}

\section{Notas}

1 Richard Hornby distingue cinco categorías metadramáticas: el teatro dentro del teatro, la representación de una ceremonia dentro de una obra dramática, el juego de papeles o 
"el papel dentro del papel," las referencias a la literatura y a la vida, y la autorreferencialidad dramática (32).

2 Los datos de la edición Apex indican que Torres Molina escribió Extraño juguete entre finales de 1976 y principios de 1977. La obra se estrenó en el teatro Payró de Buenos Aires el 20 de julio de 1977 en un momento de declive en la escena argentina causado por las medidas sofocantes impuestas a los creadores artísticos ("Two Feminist," Foster 144). Teniendo en cuenta que el golpe militar del general Videla se realizó el 24 de marzo de 1976, se entiende que la acción de Extraño juguete no contenga referencias directas a la situación política del momento.

3 Nótese que el término juguete se aplica en ocasiones a "una obra teatral breve y ligera" (María Moliner 2: 196b).

4 El distanciamiento es una de los recursos utilizados en el teatro épico. Bertold Brecht y Erwin Piscator acuñaron el término teatro épico para señalar un estilo teatral que rompe con la poética aristótelica que busca la empatía del público con los personajes y persigue un efecto catártico de liberación. Diferentes técnicas de distanciamiento opuestas al teatro naturalista contribuyen a romper la ilusión teatral para provocar la reflexión y la participación activa del espectador en el proceso de interpretación (Luzuriaga 47-48). En Una noche cualquiera, la tecnología (cámaras y monitores) interrumpe desde un principio la idea de un teatro realista convencional.

5 El cambio de papeles voluntario puede presentarse en forma de un personaje diferente o simplemente como un falso comportamiento y actitud. Sin embargo, cuando es involuntario puede tener causas externas, ajenas al personaje, propiciarse por debilidades internas o por una combinación de ambos factores. El tipo alegórico es más sutil, puesto que está relacionado con la referencialidad literaria más que estrictamente a un cambio de papel dentro del papel (Hornby 73-75).

6 El diálogo y las acotaciones enfatizan la marcada carga erótica de la escena:

MARCELO: ( $A$ Luli). ¿Así que vos organizaste todo esto? (Mientras habla la comienza a desvestir).

LULI: (Nerviosa) Hace tiempo que quería conocerte más... pero PEPE es muy posesivo. MARCELO: (Irónico). Me imagino...

(Los tres se unen en un abrazo erótico. Y luego, desaparecen en la oscuridad. Sólo se escuchan risas, exclamaciones, grititos, etc. Por los sonidos se percibe una creciente excitación en los tres. Unos segundos después se escucha el sonido amplificado de un timbre de puerta de calle, amplificado)

LULI: (Reaparece en la luz mientras se pone encima lo que MARCELO le había quitado). Deben ser las bebidas. Ya vengo. (27)

${ }^{7}$ Musetti quiere llegar a la intimidad de Marisa, que le cuente su "primera vez," su "primer hombre," y "con detalles," con "muchos detalles" (41).

8 Toda la acción se desarrolla en el interior de una casa que se representa mediante el espacio central y los pasillos norte, este y oeste, iluminados en su desembocadura al espacio central. El pasillo oeste da a la puerta de la calle, es la única salida al exterior. El público tiene acceso al teatro por el pasillo sur.

${ }^{9}$ La canción "Y dale alegría a mi corazón" pertenece al álbum titulado Tercer Mundo (1990). La letra de la canción sigue así:

Y dale alegría, alegría a mi corazón es lo único que te pido al menos hoy. $\mathrm{Y}$ dale alegría, alegría a mi corazón afuera se irán la pena y el dolor.

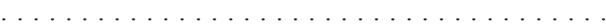

Y ya verás, las sombras que aquí estuvieron ya no estarán $\mathrm{Y}$ ya verás, que no necesitaremos nada más.

10 Las acotaciones indican el estado deplorable de las víctimas: "El aspecto de los cuatro es patético. Cada tanto MARCELO comienza a lloriquear y hace esfuerzos por controlarse. PEPE se toma el pulso y se toca el corazón. MARISA del shock, ha quedado con una expresión ausente. LULI está al borde de un ataque de histeria" (78-79). 
${ }_{11}$ Pepe, sentado en el banquillo de los acusados, finalmente confiesa que estuvo involucrado en la muerte del marido de Luli. Sus amigos, los milicos, se encargaron del caso mientras utilizaban unos galpones de su propiedad como centros de detención clandestinos. Marcelo, el actor de moda, trabajó como confidente de la policía. Le encontraron en posesión de una gran cantidad de cocaína, y para redimir su pena le propusieron convertirse en confidente. Incluso Marisa, que piensa que ella no ha hecho nada, también es acusada por estar del lado siempre de los que ostentan el poder sin plantearse cuestiones éticas o morales.

12 La situación evoca las "confesiones" y "arrepentimientos" de 1995, año en que se abrieron nuevas investigaciones sobre las acciones de la dictadura militar. En 1995 el capitán Adolfo Scilingo, uno de los altos cargos del ESMA (Escuela de Mécanica de la Armada), declaró públicamente los abusos de poder que el ejército realizó y las prácticas de terrorismo de estado. Las víctimas eran detenidas en campos clandestinos y arrojadas al mar, en ocasiones todavía vivas. La confesión de Scilingo conmocionó al país y propició el inicio de numerosas confesiones sobre el destino de muchos desaparecidos, y los diferentes métodos utilizados. El general Martín Balza se dirigió al país para confirmar las prácticas ilegales y las violaciones de derechos humanos que el ejército cometió durante la dictadura, y pidió perdón a los familiares de los desaparecidos. Balza reconoció públicamente que nadie está obligado a obedecer órdenes que atentan contra la moral y se apartan de las leyes y regulaciones castrenses (Valdéz 71-72). Balza, como Jefe del Ejército, asumía las responsabilidades por los errores cometidos en las instituciones militares y declaraba el 25 de abril de 1995: "Sin eufemismos digo claramente: Delinque quien vulnera la Constitución Nacional. Delinque quien imparte órdenes inmorales. Delinque quien cumple órdenes inmorales. Delinque quien, para cumplir un fin que cree justo, emplea medios injustos, inmorales." Para ver la declaración completa dirigirse a: $<\underline{\mathrm{http}}$ //www.nuncamas.org/document $/ \mathrm{militar} /$ balza95.htm $>$.

${ }^{13}$ Se pueden dividir dos tipos de ceremonias: las que se realizan en el escenario y las que nunca se llevan a cabo, ya sea por interrupción, ineptitud o corrupción. Las primeras conllevan un sentimiento de orden, armonía y alegría que se asocia a un tono cómico en el drama; las que no se realizan engendran emociones de discordia, desorientación y tristeza relacionadas con un modo trágico (Hornby 55-56).

${ }^{14}$ Mario Cabezas utiliza el término metagonista para describir al protagonista que se desprende de "la 'parte' asignada por el autor," y en consecuencia es capaz de cambiar su destino $(80)$.

15 Argentina hoy todavía clama justicia por los abusos de poder perpretados durante la dictadura militar. Las heridas continúan sin cicatrizar y muchos de los grupos sociales implicados continúan pidiendo justicia. El 24 de marzo de 2006, fecha del aniversario de los 30 años del golpe militar, el gobierno argentino declaró la jornada como día festivo. Numerosos carteles negros con el lema de "Nunca más" y las fechas 1976-2006 se instalaron en la capital. A esa fecha como indica el corresponsal del diario El País (Madrid) en Buenos Aires, Javier Marirrodriga, se esperaba que el presidente Kirchner anulara los indultos que firmó Carlos Menem entre 1989 y 1990 por los que perdonaba las penas de cadena perpetua a los líderes de la dictadura. Marirrodriga menciona la polémica generada por el gobierno argentino ante la declaración de dicho día como festivo. Recuérdese que en España, el 18 de julio, fecha del Alzamiento Nacional e inicio de la guerra civil, dejó de ser festivo después de la muerte de Franco.

\title{
Obras citadas
}

\author{
Balza, Martín. "Declaración." $<\underline{\text { http://www.nuncamas.org/document/militar/ }}$ \\ balza95.htm>.
}


Bixler, Jacqueline Eyring. "For Women Only?: The Theater of Susana Torres Molina." Latin American Women Dramatists: Theater, Texts, and Theories. Bloomington: Indiana UP, 1998: 215-33.

. "Games and Reality on the Latin American Stage." Latin American Literary Review 12 (1984): 22-35.

Cabezas, Mario A. "Introducción a la teoría de la transgresión en el metateatro." Selecta 12 (1991): 79-83.

Foster, David William. "Two Feminist Dramatic Versions of Patriarchal Repression." Violence in Argentine Literature: Cultural Responses to Tyranny. Columbia: U of Missouri P, 1995: 135-56.

"Identidades polimórficas y planteo metateatral en Extraño juguete de Susana Torres Molina." Alba de América 12.137 (1989): 77-112.

Fowlie,Wallace. Dionysus in Paris: A Guide to Contemporary French Theater. Gloucester, Mass.: Peter Smith, 1971.

Funes, Patricia. "Nunca más. Memorias de las dictaduras en América Latina." La imposibilidad del olvido. Recorridos de la memoria en Argentina, Chile y Uruguay. Ed. Bruno Groppo y Patricia Flier. La Plata: Ediciones Al Margen, 2001:43-61.

Groppo, Bruno. "Traumatismos de la memoria e imposibilidad del olvido en los países del Cono Sur." La imposibilidad del olvido. Recorridos de la memoria en Argentina, Chile y Uruguay. Ed. Bruno Groppo y Patricia Flier. La Plata: Ediciones Al Margen, 2001: 19-42.

. y Patricia Flier, eds. "Introducción." La imposibilidad del olvido. Recorridos de la memoria en Argentina, Chile y Uruguay. La Plata: Ediciones Al Margen, 2001: 11-18.

Hornby, Richard. Drama, Metadrama and Perception. Lewisburg: Bucknell UP, 1986.

Larson, Catherine. "Games and Gender Issues." Games and Play in the Theater of Spanish American Women. Lewisburg: Bucknell UP, 2004: 95-116.

Luzuriaga, Gerardo. Del absurdo a la zarzuela: Glosario dramático, teatral y crítico. Ottawa: GIROL, 1993.

Marirrodriga, Jorge. “Argentina recuerda hoy los 30 del golpe militar." EL PAÍS.es (Madrid), 24-03-2006.

Moliner, María. Diccionario de uso del español. 2 vols. Madrid: Gredos, 1991.

Monti, Ricardo. “Prólogo.” Extraño juguete. Buenos Aires: Apex, 1978: 7-9.

Novaro, Marcos y Vicente Palermo, eds. La historia reciente: Argentina en democracia. Buenos Aires: Edhasa, 2004.

Palermo, Vicente. "Entre la memoria y el olvido: represión, guerra y democracia en la Argentina." La historia reciente: Argentina en democracia. Ed. Marcos Novaro y Vicente Palermo. Buenos Aires: Edhasa, 2004: 169-91.

Savater, Fernando. Teoría y presencia de la tortura en España. Barcelona: Editorial Anagrama, 1982. 
Torres Molina, Susana. Extraño juguete. Buenos Aires: Apex, 1978.

. Una noche cualquiera. Sevilla: Área de Cultura, Ayuntamiento de Sevilla, 1999.

Valdez, Patricia. "Tiempo óptimo para la memoria." La historia reciente: Argentina en democracia. Ed. Marcos Novaro y Vicente Palermo. Buenos Aires: Edhasa, 2004: 63-82. 